\title{
Periodontal Disease, Tooth Loss and Incident Rheumatoid Arthritis: Results from the First National Health and Nutrition Examination Survey and its Epidemiologic Follow-up Study
}

\author{
Ryan T. Demmer, PhD, MPHa, Jerry A. Molitor, MD, PhD ${ }^{b}$, David R. Jacobs Jr., PhDc,d, and \\ Bryan S. Michalowicz, DDS \\ aDepartment of Epidemiology, Mailman School of Public Health, Columbia University, New York, \\ NY \\ bepartment of Medicine, University of Minnesota, Minneapolis, MN \\ 'Division of Epidemiology and Community Health, School of Public Health, University of \\ Minnesota, Minneapolis, MN \\ dDepartment of Nutrition, University of Oslo, Oslo, Norway \\ eDepartment of Developmental and Surgical Sciences, University of Minnesota, Minneapolis, MN
}

\begin{abstract}
Aims-Infection may be a rheumatoid arthritis (RA) risk factor. We examined whether signs of periodontal infection were associated with RA development in NHANES I \& NHEFS.

Materials and Methods-In 1971-1974, 9,702 men and women aged 25-74 were enrolled and surveyed longitudinally $(1982,1986,1987,1992)$. Periodontal infection was defined by baseline tooth loss or clinical evidence of periodontal disease. Baseline $(\mathrm{n}=138)$ and incident $(\mathrm{n}=433)$ RA cases were defined via self-report physician diagnosis, joint pain/swelling, ICD-9 codes (714.0714.9), death certificates, and/or RA hospitalization.
\end{abstract}

Results-Adjusted odds ratios (ORs) [95\%CI] for prevalent RA in gingivitis and periodontitis (vs. healthy) were $1.09[0.57,2.10]$ and $1.85[0.95,3.63]$; incident RA ORs were $1.32[0.85,2.06]$ and $1.00[0.68,1.48]$. The ORs for prevalent RA among participants missing 5-8, 9-14, 15-31 or 32 teeth (vs. $0-4$ teeth) were 1.74[1.03,2.95], 1.82[0.81,4.10], 1.45[0.62,3.41] and 1.30[0.48,3.53]; ORs for incident RA were 1.12[0.77,1.64], 1.67[1.12,2.48], 1.40[0.85,2.33] and 1.22[0.75,2.00]. Dose-responsiveness was enhanced among never-smokers. The rate of death or loss-to-follow-up after 1982 was 2-4 fold higher among participants with periodontitis or missing $\geq 9$ teeth (vs. healthy participants).

Conclusions-Although participants with periodontal disease or $\geq 5$ missing teeth experienced higher odds of prevalent/incident RA, most ORs were nonstatistically significant and lacked doseresponsiveness. Differential RA ascertainment bias complicated the interpretation of these data.

\section{Keywords}

Rheumatoid Arthritis; Periodontal; Infections; Cohort Studies; Bias

Rheumatoid Arthritis (RA) is a chronic, disabling disease affecting $0.5-1 \%$ of the population(Tobon et al., 2010). Early and aggressive interventions have reduced the rate of

Address for Correspondence: Ryan Demmer, PhD, 722 W. $168^{\text {th }}, 7^{\text {th }}$ Floor, New York, NY 10040, rtd2106@ columbia.edu. 
progression of the disease and its long-term disability(Klareskog et al., 2009). Nevertheless, the majority of patients continue to require lifelong, often expensive or inaccessible therapy, and have increased mortality, particularly due to cardiovascular disease even with more aggressive and modern treatments(Gabriel, 2008). Thus, there is a strong need to understand the risk factors and preclinical disease pathways leading to clinical RA, to facilitate preclinical RA intervention.

The most important known risk factors for RA are genetic. The "shared epitope" (SE) - a short peptide sequence found in multiple HLA-DR alleles - is the most significant genetic risk factor, and cigarette smoking interacts with SE alleles to increase the risk for autoantibodies against citrullinated peptides that predict risk for RA(Klareskog et al., 2009).

Microbial exposures have been suggested as a risk factor for RA(Rosenstein et al., 2004). Periodontal disease, which is partly caused by gram-negative anaerobic bacterial species(Haffajee and Socransky, 1994, Papapanou et al., 1997, Timmerman et al., 2001, van Winkelhoff et al., 2002, Van der Velden et al., 2006, Paster et al., 2006, Demmer et al., 2008c), shares several pathobiological features with RA(Rosenstein et al., 2004, Culshaw et al., 2011). Two recent small clinical trials have demonstrated that periodontal therapy among RA patients can reduce RA disease activity(Al-Katma et al., 2007, Ortiz et al., 2009) providing evidence that periodontal infections might exacerbate RA severity. Others have reported associations between periodontitis and RA in cross-sectional studies(de Pablo et al., 2008, Pischon et al., 2008, de Pablo et al., 2009). Such associations, however, may arise from shared environmental or genetic risk factors that result in similar pathobiology. Importantly, associations between periodontitis and RA have been observed following adjustment for smoking, which is the most important known shared environmental risk factor(de Pablo et al., 2008, de Pablo et al., 2009, Molitor, 2009). Thus, periodontal disease pathobiology might contribute to the development of RA or vice versa.

Longitudinal analyses can help to establish the temporal relationship between clinical periodontal disease and RA. The only available longitudinal data that followed the development of RA subsequent to the assessment of periodontal infection suggest increased incidence of RA in never smokers with moderate to severe periodontitis in the Atherosclerosis Risk in Communities (ARIC) cohort(Molitor, 2009).

The First National Health and Nutrition Examination Survey (NHANES I) and its epidemiological follow - up study (NHEFS) provide a unique opportunity to examine the association between prevalent periodontal disease and both prevalent and incident RA because: i) both medical and dental evaluations were conducted concurrently at baseline; and ii) the large nationally representative sample and long longitudinal follow-up period enabled the accumulation of adequate RA event rates. We tested the hypothesis that baseline evidence of historical exposure to periodontal infections (assessed via clinical periodontal examination and tooth loss status) can predict both prevalent and incident RA in the nationally representative, population-based setting of NHANES I and NHEFS. Based on findings from the ARIC study(Molitor, 2009), we also hypothesized that the association with incident RA would be strongest in never smokers. We have included the cross-sectional aims in our current report to establish consistency with previous research.

\section{METHODS}

Details concerning the design of NHANES I and its Epidemiologic Follow-up Study have been previously published.(DeStefano et al., 1993) Briefly, NHANES I was a national probability sample of the non-institutionalized U.S. population aged 1-74 years, conducted during 1971-1974. NHEFS is a longitudinal study including all persons initially 25-74 years 
of age who completed a medical examination at NHANES I $(14,407)$. The NHEFS is comprised of four follow-up studies occurring during the four periods of $1982-1984,1986$, 1987 and 1992. The 1986, 1987 and 1992 follow-up assessments utilized the same design and data collection procedures developed in the 1982-1984 NHEFS, except that a 30-minute computer-assisted telephone interview was administered rather than a personal interview. No physical measurements were taken during the 1986 - 1992 exams. The 1986 NHEFS was conducted for members of the NHEFS cohort who were 55-74 years of age at their baseline examination and not known to be deceased at the 1982-84 NHEFS $(3,980)$. The $1987(11,750)$ and $1992(11,195)$ follow-up evaluations were conducted for the entire surviving cohort. Ninety-six percent of the study population was successfully traced at some point through the 1992 follow-up. Tracing rates for each completed wave ranged from $90 \%$ to $94 \%$ and interview rates ranged from $91 \%$ to $96 \%$ of those traced.

\section{Periodontal Disease Assessment}

Dental examiners were trained to follow a written set of objective standards to narrow the range of examiner variability by eliminating conditions known to be sources of disagreement.(Kelly and Harvey, 1979, Miller and National Center for Health Statistics (U.S.), 1973)

The Periodontal Index (PI)(Russell, 1956) was used to assess the presence or absence of periodontal disease for each tooth (maximum $=32$ ) by assigning scores (PI range $=0-8$ ) based on gingival inflammation extent, the presence/absence of periodontal pockets - i.e. attachment loss according to Russell(Russell, 1956) - and tooth mobility. As previously described(Wu et al., 2000), these tooth level assessments, in combination with tooth counts, were used to assign a periodontal classification to all participants as follows: i) healthy periodontium: no teeth with periodontal disease or not more than 1 tooth with mild gingivitis if 20 or more teeth were examined; ii) gingivitis: at least 1 tooth with mild gingivitis or a worse condition that did not fit the category for either no periodontal disease or periodontitis; iii) periodontitis: 4 or more teeth with "overt pockets" (i.e. attachment loss) or worse conditions.

\section{Rheumatoid Arthritis Definitions}

Baseline (prevalent) rheumatoid arthritis was defined by either participant self-report of physician diagnosis or physical examination data corresponding to criteria 1-4 of the American Rheumatism Association 1987 criteria(Arnett et al., 1988).

Incident rheumatoid arthritis was defined as follows: i) death certificate: International Classification of Death, Ninth Revision (ICD)-9 code in the range of 714.0-714.9 (two cases included based solely on ICD-9 codes of 714.8-714.9), or rheumatism otherwise listed on the death certificate; ii) self-reported physician diagnosis (based on 1986-1992 interviews); or iii) health care facility stay with a discharge diagnosis of rheumatism (ICD-9 codes).

\section{Risk Factor Assessment}

As previously described(Demmer et al., 2008a), confounding variables related to RA risk, periodontal infection and/or indicative of healthy lifestyle were collected during the baseline evaluation including age, gender, race (African American, Caucasian, Other), poverty index (total household income in the numerator and total income necessary to maintain the family on a nutritionally adequate food plan in the denominator; values $>1$ indicate incomes above poverty), education level (completed $3^{\text {th }}$ grade, $9^{\text {th }}-12^{\text {th }}$ grade, some college, college graduate), body mass index (BMI, weight in kilograms divided by height in meters squared), physical activity. Detailed cigarette smoking history information was collected on a subset 
of participants at baseline and for the remaining participants during the 1982-1984 followup. This approach has been validated(Machlin et al., 1989, McLaughlin et al., 1987).

\section{Statistical analysis}

SAS software version 9.2 was used to conduct multivariable logistic regression analysis to assess the association between baseline periodontal disease or tooth loss level and the cumulative incidence of rheumatoid arthritis. Participants were classified as being either periodontally healthy or having gingivitis or periodontitis, as described above. Tooth loss was also considered as a surrogate marker of historical periodontal infection. Participants were categorized as having 0-4 missing teeth (MT), 5-8 MT, 9-14 MT, 15-31 MT; or 32 MT. The SURVEYLOGISTIC(SAS) procedure in SAS was used to account for the complex survey design (based on survey locations 1-65). Proportional hazards survival analysis was performed (using PHREG) although these findings should be interpreted cautiously as PHREG is unable to account for the NHANES stratification, clustering and sample weights; this limitation underestimates variance but does not bias the reported hazard ratios. Our multivariable models were based on the following currently established risk factors for RA: smoking behaviors, age and gender; no HLA genotypes or RA family history data were available. Additional variables such as education, race, physical activity level and poverty index were included as surrogates of socio-economic status and/or healthy lifestyle. To summarize participant characteristics (i.e., Table 1) we presented unweighted estimates to give a better sense of the characteristics of the actual data and participants analyzed.

A secondary analysis considered only RA outcomes identified via health care facility discharge records to reduce the potential for bias related to inaccurate self-report of RA.

Interaction models explored the aforementioned associations among smoking subgroups based on a priori evidence of stronger associations among never smokers(Molitor, 2009).

Incident RA cases were predominantly determined via participant self-report during the interview. The first interview to specifically ask about RA was not conducted until 19861987. Because being lost-to-follow-up (LTF) or dying after 1982 would have been related to incident RA underreporting, and was strongly associated with elevated baseline periodontal status and age, a bias might have been induced. Specifically, NHEFS participants with elevated levels of periodontal disease were less likely to have reported incident RA to the study and were therefore differentially misclassified as RA-free. We opted to keep participants who died or were LTF after 1982 in the analysis because of the potential to obtain information about incident RA occurring before 1986 from health facility records and death certificates.

\section{RESULTS}

Dental examinations were performed on 11,375 participants during NHANES I. We excluded 1,052 who were never traced, an additional 604 with missing data and an additional 17 due to uncertainty regarding the date of incident RA relative to the baseline examination leaving 9,702 for cross-sectional analysis. One hundred thirty-eight participants had RA at baseline, leaving 9,564 participants for longitudinal analysis. Demographic characteristics for the NHANES I participants have been described previously(Demmer et al., 2008a) and are presented in table 1. Having gingivitis, periodontitis or relatively advanced tooth loss was associated with higher age, male gender, smoking, lower SES and other suboptimal health measures.

The rates of death or LTF after the 1982 examination among participants with a healthy periodontium, gingivitis or periodontitis, respectively, were $8 \%, 13 \%$ and $24 \%$; rates across 
the five tooth loss categories were $8 \%, 10 \%, 17 \%, 21 \%$, and $31 \%$. The mean age of participants with death or LTF after 1982 was approximately 10 years higher than participants who completed a follow up interview after 1982.

\section{Cross-sectional Association between Periodontal Status and Rheumatoid Arthritis}

The prevalence of RA in the NHANES I survey was $1.4 \%$ (138 cases). After multivariable adjustment, relative to healthy participants, those with periodontitis had an approximate twofold increase in the odds of prevalent RA. Relative to those with $0-4$ missing teeth, participants with 5-8 missing teeth experienced an increase in the odds of prevalent RA (table 2); ORs among participants missing $>8$ teeth were not statistically significantly different than 1.0 (table 2).

\section{Longitudinal Association between Periodontal Status and Rheumatoid Arthritis}

The cumulative incidence of RA during 20 years of follow-up was $4.7 \%$ (433 cases) and the majority of cases were determined via self-report physician diagnosis alone (79\%). An additional $11 \%$ were determined via facility discharge alone. The remaining $10 \%$ were based on a combination of self-report, facility discharge and death certificate; no cases were determined via death certificate alone. Females had higher odds of incident RA: $\mathrm{OR}=1.47(95 \% \mathrm{CI}: 1.10,1.96)$. Five-year higher baseline age also had increased odds of incident RA: OR=1.10 $(1.09,1.11)$. The odds ratios for former or current smoking vs. never smoking were positively, yet not statistically significantly associated with incident RA and were as follows: $1.44(0.92,2.26)$ and $1.21(0.79,1.85)$, respectively.

Participants with gingivitis at baseline experienced a nonstatistically significant increased odds of RA development relative to healthy participants (Table 3). There were no evident associations between either periodontitis or edentulism and incident RA (Table 3). When considering only 88 incident RA cases diagnosed via hospital discharge, the respective ORs for gingivitis, periodontitis and edentulism were $1.39(0.58,2.21), 1.28(0.54,3.06)$ and $1.24(0.47,3.21)$.

Consistent with the cross-sectional results, individuals with intermediate tooth loss (9-14 missing teeth) experienced an increase in the odds of incident $\mathrm{RA}(\mathrm{p}<0.05)$ relative to participants missing $0-4$ teeth (Table 3 ). The odds ratios observed among participants either missing 15-31 teeth or being edentulous were attenuated as compared to results for participants missing 9-14 teeth (Table 3). In survival analysis, the adjusted risk ratios for incident RA among participants missing 5-8, 9-14, 15-31 or 32 teeth vs. 0-4 missing teeth were $1.10(0.75,1.60), 1.46(1.00,2.13), 1.09(0.73,1.62)$ and $1.16(0.78,1.72)$, respectively. When considering only 88 RA cases determined via hospital discharge, odds ratios for incident RA among participants missing 5-8, 9-14, 15-31 or 32 teeth vs. $0-4$ missing teeth were $1.08(0.40,2.923), 1.45(0.52,4.04), 1.52(0.53,4.37), 1.36(0.52,3.56)$, respectively. The association between tooth loss and incident RA tended to be more pronounced among participants with either gingivitis or periodontitis ( $\mathrm{p}$ for interaction $=0.05$; Figure 1 ).

Associations between periodontal disease, tooth loss and incident RA were more doseresponsive among never smokers (Table 4). While neither gingivitis nor periodontitis was statistically significantly associated with incident RA the p-value for linear trend across levels of periodontal disease was 0.06 . Among never smokers, increased tooth loss was associated with a monotonic increase in the odds for incident RA (p-value for linear trend across tooth loss categories $=0.04$ ). Edentulous participants (relative to those missing 0-4 teeth) experienced a statistically significantly increased OR of incident RA: 1.92(1.00,3.66). 


\section{DISCUSSION}

Participants with periodontal disease or $\geq 5$ missing teeth experienced higher odds of prevalent and incident RA. Most - but not all - of the reported ORs were not statistically significant and the observed patterns of RA prevalence and incidence across increasing levels of periodontal disease or tooth loss did not show dose-responsiveness which favors a null conclusion. However, while few odds ratios were statistically significant, they were consistently $>1.0$ for both gingivitis and tooth loss exposures, but not periodontits, predicting incident RA (Table 3). The OR for periodontitis predicting incident RA was noticeably, but not significantly, >1.0 among never smokers (Table 4). Under the null hypothesis of no association, one would have expected the estimated ORs to be more equally distributed above and below 1.0. Despite the large dataset and long follow-up period, several characteristics of these data, as discussed below, make it difficult to draw firm conclusions in favor of or against the null hypothesis based on these results alone.

To our knowledge, only two other studies have reported on the association between periodontal infection and risk for incident RA. Data from the Atherosclerosis Risk in Communities (ARIC) study demonstrated an increased risk of incident RA among participants with moderate/severe periodontitis which was driven by positive associations among never smokers(Molitor, 2009). An important limitation of the ARIC data is that only 33 incident RA cases had accumulated. Our current results among never smokers support these preliminary ARIC results, although the exact nature of this interaction requires further examination. Regardless, this finding reduces the potential for any associations to have been explained by residual smoking-related confounding.

In contrast, a recent publication from the Nurses Health Study (NHS) found no association between periodontal disease and incident RA(Arkema et al., 2010). However, the primary definition of exposure to periodontal infection was defined via self-report of periodontal surgery or tooth loss in the preceding two years which likely misclassified many individuals with periodontal disease as periodontally healthy. In our current report from NHANES, participants received baseline clinical periodontal evaluations and over 400 incident RA cases were reported in a nationally representative sample of U.S. adults. We believe the higher number of cases relative to other studies likely resulted from longer follow up (20 years in NHANES I/NHEFS vs. 8-12 years in ARIC and NHS, respectively), a broader age range, and inclusion of self-reported physician diagnosis.

The potential for periodontal disease to contribute to the development of RA is biologically plausible and has been previously hypothesized(Rosenstein et al., 2004, Lundberg et al., 2010). Chronic periodontal infections involve multiple gram-negative bacteria, including Porphyromonas gingivalis(Paster et al., 2006), which engage the innate immune system and result in the chronic activation of antigen-presenting cells in the infected tissues. $P$. gingivalis is unique among periodontal pathogens in that it possesses a peptidyl arginine deiminase(McGraw et al., 1999, Wegner et al., 2010), which can citrullinate host peptides that in turn may elicit an anti-citrulline autoimmune response among genetically susceptible individuals. Accordingly, $P$. gingivalis induced extra-oral inflammatory lesions and periodontitis have been shown to promote or exacerbate arthritis in a animal models(Bartold et al., 2010, Cantley et al., 2011).

Accordingly, our biological hypothesis linking infection to RA partly relies on complex and relatively rare compound susceptibility genotypes(Klareskog et al., 2009) that likely exist in only a small subgroup of the NHANES population; therefore, the magnitude of the reported associations are likely diluted by many nonsusceptible participants in our analysis. Early epidemiologic work establishing cigarette smoking as an environmental risk for RA faced 
similar initial challenges in that they lacked data on HLA genotypes. These initial studies found weak and somewhat inconsistent associations between smoking duration/intensity and RA (Karlson et al., 1999, Criswell et al., 2002). Subsequent publications that could explore gene-environment interactions (Padyukov et al., 2004, Klareskog et al., 2006) demonstrated that in the context of relevant genetic susceptibilities, the RA risk posed by tobacco smoke was substantial. It is noteworthy that our current results for NHANES, which cannot incorporate data on HLA genotypes, also demonstrate weak, nonlinear, nonstatistically significant associations between smoking status and incident RA despite the fact there is very likely to be a strong causal association in genetically susceptible groups.

Our current hypothesis suggests an alternate environmental risk factor - microbes - as a possible etiologic agent in the development of RA. While our findings minimize the likelihood that periodontal infections pose meaningful risk for RA development in the general population, more focused studies in genetically susceptible populations might be more informative as was the historical case with smoking and RA risk.

Our incident RA outcome assessments were primarily based on participant self-report which created a high likelihood of biased incident RA ascertainment. NHANES participants with advanced tooth loss and periodontitis received fewer follow-up interviews as compared to participants who were periodontally healthy or missing only $0-4$ teeth at baseline. If underreporting of incident RA occurred at a higher rate among participants with advanced tooth loss and periodontal disease (as compared to periodontally healthy participants), and the experience in the observed participants was applicable to the experience in participants who died or were lost to follow-up after 1982, the observed risk in these groups would be biased towards the null. Alternatively, since the case definition of RA was primarily determined by self-report the possibility of another form of ascertainment bias exists, in which participants with other arthritides might have falsely reported rheumatoid arthritis to the study.

The current approach considered tooth loss as a surrogate exposure for historical periodontal infection since tooth loss is often the result of bacteria-induced, inflammatory processes and is a strong correlate of clinical periodontal disease (Jansson et al., 2002). Tooth loss is generally considered to be a reasonable surrogate measure of infectious exposure when investigating associations between periodontal infection and chronic disease outcomes( $\mathrm{Wu}$ et al., 2000, Desvarieux et al., 2003, Joshipura et al., 2003, Hung et al., 2003, Desvarieux et al., 2004, Volzke et al., 2006, Demmer et al., 2008b). Although, tooth loss is produced by many causes, such as caries which might be highly relevant in this population, recent data demonstrate that caries prevalence is related to increased periodontal disease prevalence (Mattila et al., 2010). Moreover, dental procedures including tooth extractions(Rajasuo et al., 2004a, Rajasuo et al., 2004b, Kinane et al., 2005) have been shown to induce bacteremias thereby enabling oral microbes to gain systemic access irrespective of treatment indication and as importantly oral microbes, once systemic, can remain viable(Rafferty et al., 2011). Finally, in these data greater tooth loss was more strongly associated with incident RA among participants with evidence of baseline gingivitis and periodontitis leading to a hypothesis that tooth loss might only be relevant in the context of existing oral infection/inflammation.

Russell's Periodontal Index (PI) was used to summarize the clinical periodontal condition of participants (Russell, 1956). Although it did not include linear measures of attachment loss and probing depth or assess bleeding from the marginal gingiva or pocket, the Index has been shown to correlate well to clinical and radiographic diagnoses (Russell, 1956). As importantly, NHANES has only one baseline assessment of periodontal status and tooth 
number precluding a more precise characterization of periodontal status throughout the follow-up period.

We have found the associations between periodontal status, tooth loss and both prevalent and incident RA to be consistently positive in direction but nonlinear and generally not statistically significant in the nationally representative National Health and Nutrition Examination Survey and Its Epidemiological Follow-Up Study. The overall patterns observed make it difficult to draw firm conclusions but it is unlikely that periodontal infections represent a strong RA risk factor in the general U.S. population. Future studies that can reduce RA ascertainment bias, incorporate more precise measures of exposure to periodontal microbes and measure relevant HLA genotypes will be necessary for more focused causal inference and definitive conclusions.

\section{Acknowledgments}

FUNDING

This work was supported by NIH grant R00 DE-018739 to R.T.D.

\section{References}

AL-KATMA MK, BISSADA NF, BORDEAUX JM, SUE J, ASKARI AD. Control of periodontal infection reduces the severity of active rheumatoid arthritis. J Clin Rheumatol. 2007; 13:134-7. [PubMed: 17551378]

ARKEMA EV, KARLSON EW, COSTENBADER KH. A prospective study of periodontal disease and risk of rheumatoid arthritis. The Journal of Rheumatology. 2010; 37:1800-4. [PubMed: 20595268]

ARNETT FC, EDWORTHY SM, BLOCH DA, MCSHANE DJ, FRIES JF, COOPER NS, HEALEY LA, KAPLAN SR, LIANG MH, LUTHRA HS, MEDSGER TA, MITCHELL DM, NEUSTADT DH, PINALS RS, SCHALLER JG, SHARP JT, WILDER RL, HUNDER GG. The American Rheumatism Association 1987 revised criteria for the classification of rheumatoid arthritis. Arthritis Rheum. 1988; 31:315-24. [PubMed: 3358796]

BARTOLD PM, MARINO V, CANTLEY M, HAYNES DR. Effect of Porphyromonas gingivalisinduced inflammation on the development of rheumatoid arthritis. Journal of Clinical Periodontology. 2010; 37:405-11. [PubMed: 20507365]

CANTLEY MD, HAYNES DR, MARINO V, BARTOLD PM. Pre-existing periodontitis exacerbates experimental arthritis in a mouse model. Journal of Clinical Periodontology. 2011; 38:532-41. [PubMed: 21434962]

CRISWELL LA, MERLINO LA, CERHAN JR, MIKULS TR, MUDANO AS, BURMA M, FOLSOM AR, SAAG KG. Cigarette smoking and the risk of rheumatoid arthritis among postmenopausal women: results from the Iowa Women's Health Study. Am J Med. 2002; 112:46571. [PubMed: 11959057]

CULSHAW S, MCINNES IB, LIEW FY. What can the periodontal community learn from the pathophysiology of rheumatoid arthritis? Journal of Clinical Periodontology. 2011; 38(Suppl 11): 106-13. [PubMed: 21323707]

DE PABLO P, CHAPPLE IL, BUCKLEY CD, DIETRICH T. Periodontitis in systemic rheumatic diseases. Nat Rev Rheumatol. 2009; 5:218-24. [PubMed: 19337286]

DE PABLO P, DIETRICH T, MCALINDON TE. Association of periodontal disease and tooth loss with rheumatoid arthritis in the US population. J Rheumatol. 2008; 35:70-6. [PubMed: 18050377]

DEMMER RT, JACOBS DR JR, DESVARIEUX M. Periodontal disease and incident type 2 diabetes: results from the First National Health and Nutrition Examination Survey and its epidemiologic follow-up study. Diabetes Care. 2008a; 31:1373-9. [PubMed: 18390797]

DEMMER RT, KOCHER T, SCHWAHN C, VOLZKE H, JACOBS DR JR, DESVARIEUX M. Refining exposure definitions for studies of periodontal disease and systemic disease associations. Community Dent Oral Epidemiol. 2008b; 36:493-502. [PubMed: 18422705] 
DEMMER RT, PAPAPANOU PN, JACOBS DR JR, DESVARIEUX M. Bleeding on probing differentially relates to bacterial profiles: the Oral Infections and Vascular Disease Epidemiology Study. J Clin Periodontol. 2008c; 35:479-86. [PubMed: 18400025]

DESTEFANO F, ANDA RF, KAHN HS, WILLIAMSON DF, RUSSELL CM. Dental disease and risk of coronary heart disease and mortality. BMJ. 1993; 306:688-91. [PubMed: 8471920]

DESVARIEUX M, DEMMER RT, RUNDEK T, BODEN-ALBALA B, JACOBS DR JR, PAPAPANOU PN, SACCO RL. Relationship between periodontal disease, tooth loss, and carotid artery plaque: the Oral Infections and Vascular Disease Epidemiology Study (INVEST). Stroke. 2003; 34:2120-5. [PubMed: 12893951]

DESVARIEUX M, SCHWAHN C, VOLZKE H, DEMMER RT, LUDEMANN J, KESSLER C, JACOBS DR JR, JOHN U, KOCHER T. Gender differences in the relationship between periodontal disease, tooth loss, and atherosclerosis. Stroke. 2004; 35:2029-35. [PubMed: 15256677]

GABRIEL SE. Cardiovascular morbidity and mortality in rheumatoid arthritis. Am J Med. 2008; 121:S9-14. [PubMed: 18926169]

HAFFAJEE AD, SOCRANSKY SS. Microbial etiological agents of destructive periodontal diseases. Periodontol 2000. 1994; 5:78-111. [PubMed: 9673164]

HUNG HC, WILLETT W, MERCHANT A, ROSNER BA, ASCHERIO A, JOSHIPURA KJ. Oral health and peripheral arterial disease. Circulation. 2003; 107:1152-7. [PubMed: 12615794]

JANSSON L, LAVSTEDT S, ZIMMERMAN M. Prediction of marginal bone loss and tooth loss--a prospective study over 20 years. J Clin Periodontol. 2002; 29:672-8. [PubMed: 12390562]

JOSHIPURA KJ, HUNG HC, RIMM EB, WILLETT WC, ASCHERIO A. Periodontal Disease, Tooth Loss, and Incidence of Ischemic Stroke. Stroke. 2003; 34:47-52. [PubMed: 12511749]

KARLSON EW, LEE IM, COOK NR, MANSON JE, BURING JE, HENNEKENS CH. A retrospective cohort study of cigarette smoking and risk of rheumatoid arthritis in female health professionals. Arthritis Rheum. 1999; 42:910-7. [PubMed: 10323446]

KELLY, JE.; HARVEY, CR. Basic data on dental examination findings of persons 1-74 years, United States, 1971-1974. Hyattsville, Md: U.S. Dept. of Health, Education, and Welfare, Public Health Service, Office of Health Research, Statistics; 1979.

KINANE DF, RIGGIO MP, WALKER KF, MACKENZIE D, SHEARER B. Bacteraemia following periodontal procedures. J Clin Periodontol. 2005; 32:708-13. [PubMed: 15966875]

KLARESKOG L, CATRINA AI, PAGET S. Rheumatoid arthritis. Lancet. 2009; 373:659-72. [PubMed: 19157532]

KLARESKOG L, STOLT P, LUNDBERG K, KALLBERG H, BENGTSSON C, GRUNEWALD J, RONNELID J, HARRIS HE, ULFGREN AK, RANTAPAA-DAHLQVIST S, EKLUND A, PADYUKOV L, ALFREDSSON L. A new model for an etiology of rheumatoid arthritis: smoking may trigger HLA-DR (shared epitope)-restricted immune reactions to autoantigens modified by citrullination. Arthritis Rheum. 2006; 54:38-46. [PubMed: 16385494]

LUNDBERG K, WEGNER N, YUCEL-LINDBERG T, VENABLES PJ. Periodontitis in RA-the citrullinated enolase connection. Nature reviews Rheumatology. 2010; 6:727-30.

MACHLIN SR, KLEINMAN JC, MADANS JH. Validity of mortality analysis based on retrospective smoking information. Stat Med. 1989; 8:997-1009. [PubMed: 2799128]

MATTILA PT, NISKANEN MC, VEHKALAHTI MM, NORDBLAD A, KNUUTTILA ML. Prevalence and simultaneous occurrence of periodontitis and dental caries. J Clin Periodontol. 2010; 37:962-7. [PubMed: 20958340]

MCGRAW WT, POTEMPA J, FARLEY D, TRAVIS J. Purification, characterization, and sequence analysis of a potential virulence factor from Porphyromonas gingivalis, peptidylarginine deiminase. Infect Immun. 1999; 67:3248-56. [PubMed: 10377098]

MCLAUGHLIN JK, DIETZ MS, MEHL ES, BLOT WJ. Reliability of surrogate information on cigarette smoking by type of informant. Am J Epidemiol. 1987; 126:144-6. [PubMed: 3591778]

MILLER, HW. NATIONAL CENTER FOR HEALTH STATISTICS (U.S.). Plan and operation of the Health and Nutrition Examination Survey, United States-1971-1973; a description of a national health and nutrition examination survey of a probability sample of the US population 1-74 years 
of age. Rockville, Md: U.S. National Center for Health Statistics; 1973. for sale by the Supt. of Docs

MOLITOR JA, ALONSO A, WENER MH, MICHALOWICZ BS, BECK JD, GERSUK VH, BUCKNER JH, FOLSOM AR. Moderate to Severe Adult Periodontitis Increases Risk of Rheumatoid Arthritis in Non-Smokers and is Associated with Elevated ACPA Titers: The ARIC Study. Arthritis \& Rheumatism. 2009; 60:S433.

ORTIZ P, BISSADA NF, PALOMO L, HAN YW, AL-ZAHRANI MS, PANNEERSELVAM A, ASKARI A. Periodontal therapy reduces the severity of active rheumatoid arthritis in patients treated with or without tumor necrosis factor inhibitors. J Periodontol. 2009; 80:535-40. [PubMed: 19335072]

PADYUKOV L, SILVA C, STOLT P, ALFREDSSON L, KLARESKOG L. A gene-environment interaction between smoking and shared epitope genes in HLA-DR provides a high risk of seropositive rheumatoid arthritis. Arthritis Rheum. 2004; 50:3085-92. [PubMed: 15476204]

PAPAPANOU PN, BAELUM V, LUAN WM, MADIANOS PN, CHEN X, FEJERSKOV O, DAHLEN G. Subgingival microbiota in adult Chinese: prevalence and relation to periodontal disease progression. J Periodontol. 1997; 68:651-66. [PubMed: 9249637]

PASTER BJ, OLSEN I, AAS JA, DEWHIRST FE. The breadth of bacterial diversity in the human periodontal pocket and other oral sites. Periodontol 2000. 2006; 42:80-7. [PubMed: 16930307]

PISCHON N, PISCHON T, KROGER J, GULMEZ E, KLEBER BM, BERNIMOULIN JP, LANDAU H, BRINKMANN PG, SCHLATTMANN P, ZERNICKE J, BUTTGEREIT F, DETERT J. Association among rheumatoid arthritis, oral hygiene, and periodontitis. J Periodontol. 2008; 79:979-86. [PubMed: 18533773]

RAFFERTY B, JONSSON D, KALACHIKOV S, DEMMER RT, NOWYGROD R, ELKIND MS, BUSH H JR, KOZAROV E. Impact of monocytic cells on recovery of uncultivable bacteria from atherosclerotic lesions. Journal of Internal Medicine. 2011; 270:273-80. [PubMed: 21366733]

RAJASUO A, NYFORS S, KANERVO A, JOUSIMIES-SOMER H, LINDQVIST C, SUURONEN R. Bacteremia after plate removal and tooth extraction. Int J Oral Maxillofac Surg. 2004a; 33:356-60. [PubMed: 15145038]

RAJASUO A, PERKKI K, NYFORS S, JOUSIMIES-SOMER H, MEURMAN JH. Bacteremia following surgical dental extraction with an emphasis on anaerobic strains. J Dent Res. 2004b; 83:170-4. [PubMed: 14742658]

ROSENSTEIN ED, GREENWALD RA, KUSHNER LJ, WEISSMANN G. Hypothesis: the humoral immune response to oral bacteria provides a stimulus for the development of rheumatoid arthritis. Inflammation. 2004; 28:311-8. [PubMed: 16245073]

RUSSELL AL. A system of classification and scoring for prevalence surveys of periodontal disease. $\mathbf{J}$ Dent Res. 1956; 35:350-9. [PubMed: 13332137]

SAS. [Accessed December, 2010] PROC SURVEYLOGISTIC. [Online]. Available: http://support.sas.com/documentation/cdl/en/statug/63033/HTML/default/viewer.htmsurveylogistic_toc.htm

TIMMERMAN MF, VAN DER WEIJDEN GA, ARIEF EM, ARMAND S, ABBAS F, WINKEL EG, VAN WINKELHOFF AJ, VAN DER VELDEN U. Untreated periodontal disease in Indonesian adolescents. Subgingival microbiota in relation to experienced progression of periodontitis. J Clin Periodontol. 2001; 28:617-27. [PubMed: 11422582]

TOBON GJ, YOUINOU P, SARAUX A. The environment, geo-epidemiology, and autoimmune disease: Rheumatoid arthritis. J Autoimmun. 2010; 35:10-4. [PubMed: 20080387]

VAN DER VELDEN U, ABBAS F, ARMAND S, LOOS BG, TIMMERMAN MF, VAN DER WEIJDEN GA, VAN WINKELHOFF AJ, WINKEL EG. Java project on periodontal diseases. The natural development of periodontitis: risk factors, risk predictors and risk determinants. J Clin Periodontol. 2006; 33:540-8. [PubMed: 16899096]

VAN WINKELHOFF AJ, LOOS BG, VAN DER REIJDEN WA, VAN DER VELDEN U.

Porphyromonas gingivalis, Bacteroides forsythus and other putative periodontal pathogens in subjects with and without periodontal destruction. J Clin Periodontol. 2002; 29:1023-8. [PubMed: 12472995] 
VOLZKE H, SCHWAHN C, DORR M, SCHWARZ S, ROBINSON D, DOREN M, RETTIG R,

FELIX SB, JOHN U, KOCHER T. Gender differences in the relation between number of teeth and systolic blood pressure. J Hypertens. 2006; 24:1257-63. [PubMed: 16794473]

WEGNER N, WAIT R, SROKA A, EICK S, NGUYEN KA, LUNDBERG K, KINLOCH A,

CULSHAW S, POTEMPA J, VENABLES PJ. Peptidylarginine deiminase from Porphyromonas gingivalis citrullinates human fibrinogen and alpha-enolase: implications for autoimmunity in rheumatoid arthritis. Arthritis Rheum. 2010; 62:2662-72. [PubMed: 20506214]

WU T, TREVISAN M, GENCO RJ, DORN JP, FALKNER KL, SEMPOS CT. Periodontal disease and risk of cerebrovascular disease: the first national health and nutrition examination survey and its follow-up study. Archives of Internal Medicine. 2000; 160:2749-55. [PubMed: 11025784] 


\section{Clinical Relevance}

\section{Scientific rationale}

Periodontal infections are a plausible RA risk factor. Few longitudinal data sets exist that can test this hypothesis.

\section{Principal findings}

Although participants with periodontal disease or missing 25 teeth realized elevated odds of prevalent and incident RA, most ORs were nonstatistically significant and lacked dose-responsiveness. Periodontal status and tooth loss were both associated with elevated death and loss-to-follow-up rates resulting in differential RA ascertainment and possibly falsely negative conclusions.

\section{Practical implications}

The patterns observed indicate that periodontal infections are not a strong RA risk factor in the general population but cannot definitely rule out an association altogether. 


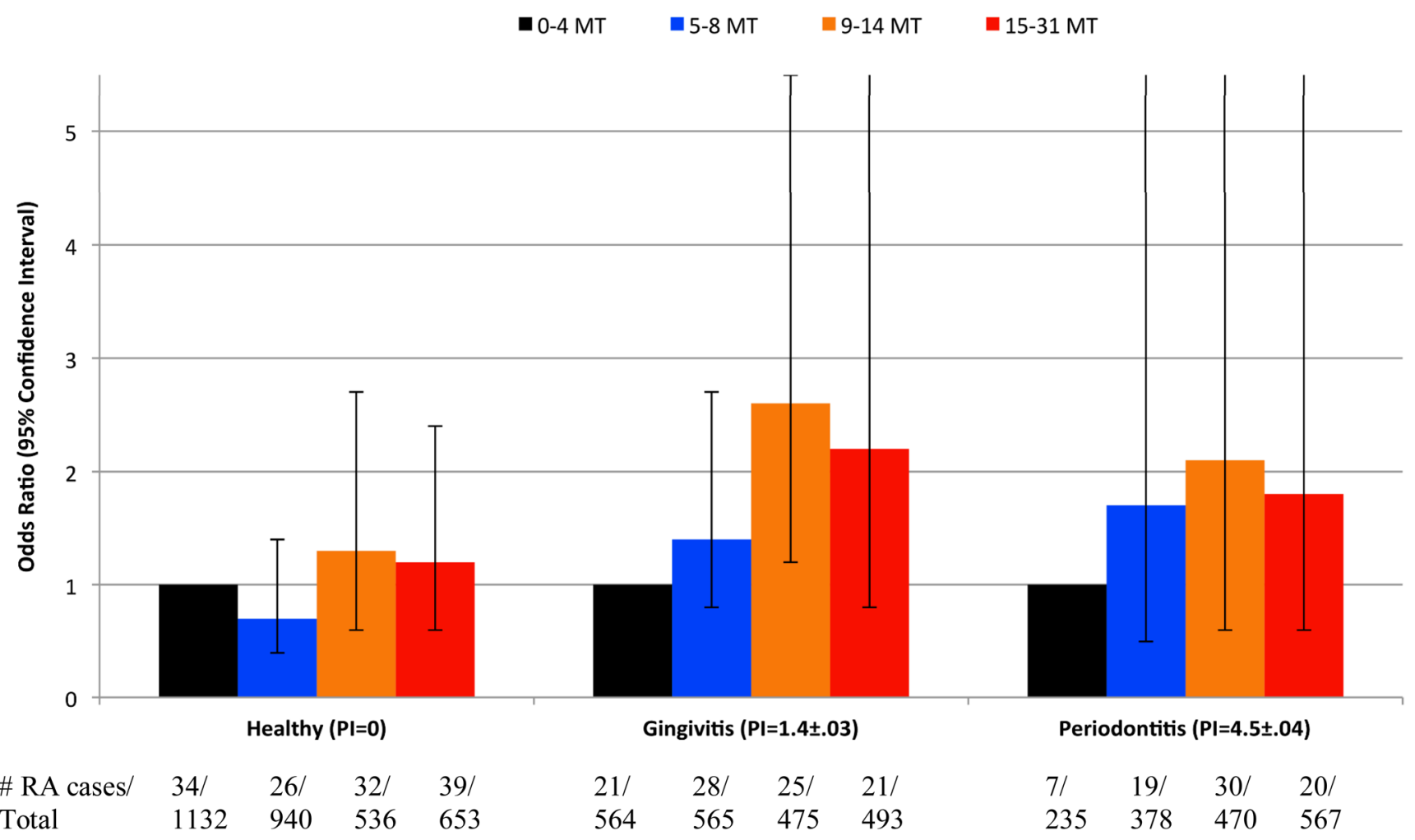

Figure 1.

Association between Baseline Tooth Loss and Incident Rheumatoid Arthritis According to Periodontal Status: Longitudinal Results from The First National Health and Nutrition Examination Survey and Its Epidemiologic Follow-up Study ( $n=7,008 ; 302$ RA cases, $p$ for interaction $=0.05$ ). Adjusted for age, sex, race, education, smoking status. body mass index, physical activity, poverty index. $\mathrm{PI}=$ mean periodontal index \pm standard error per periodontal status category; MT=missing teeth. All tooth loss odds ratios are in reference to 0-4 MT within each periodontal status category. The OR comparing participants with gingivitis and 9-14 missing teeth to $0-4$ missing teeth was statistically significant $(\mathrm{p}<0.05)$. All remaining comparisons for any tooth loss category vs. the reference ( $0-4$ missing teeth) have $p>0.05$. 


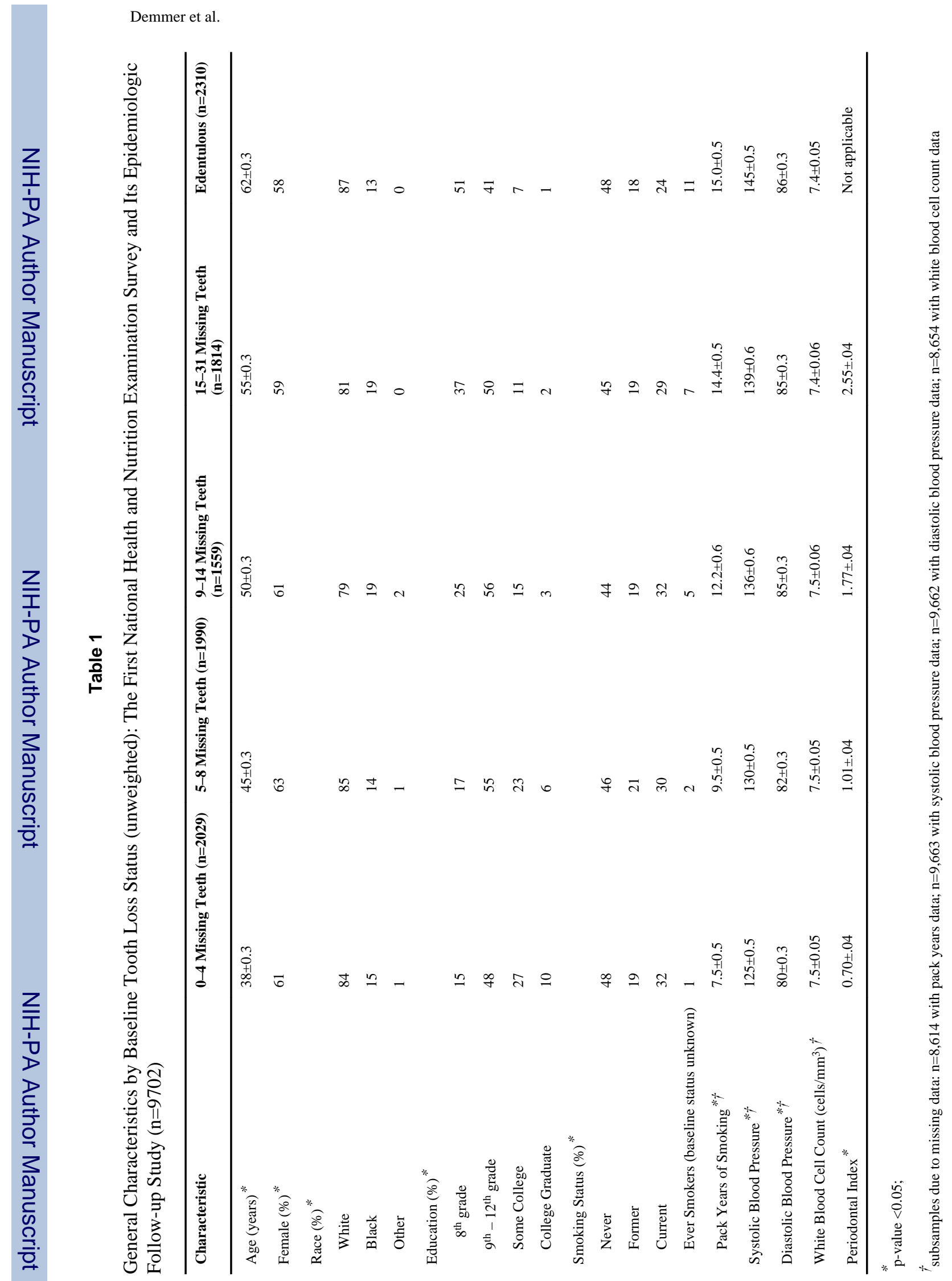

Page 14 要, 


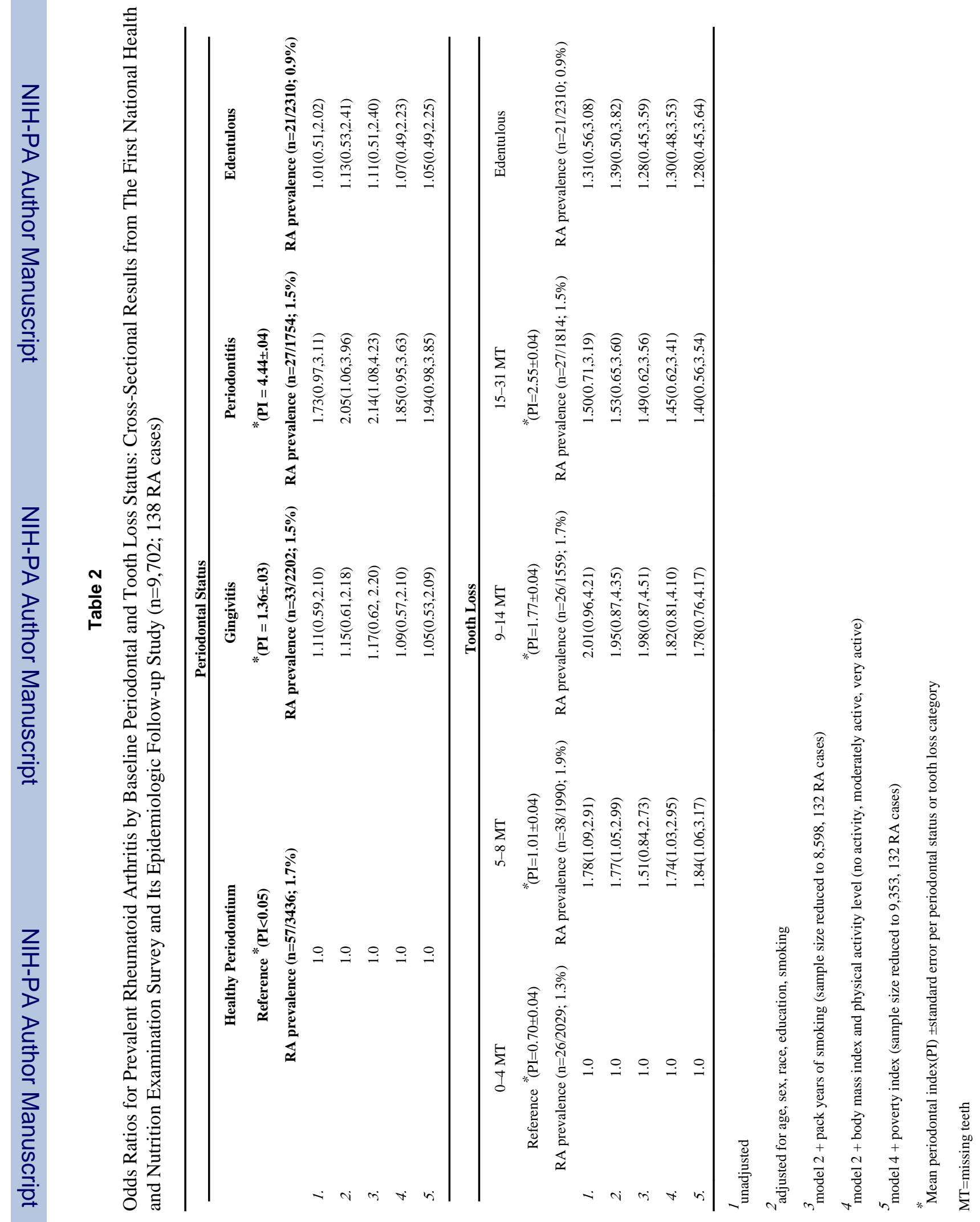




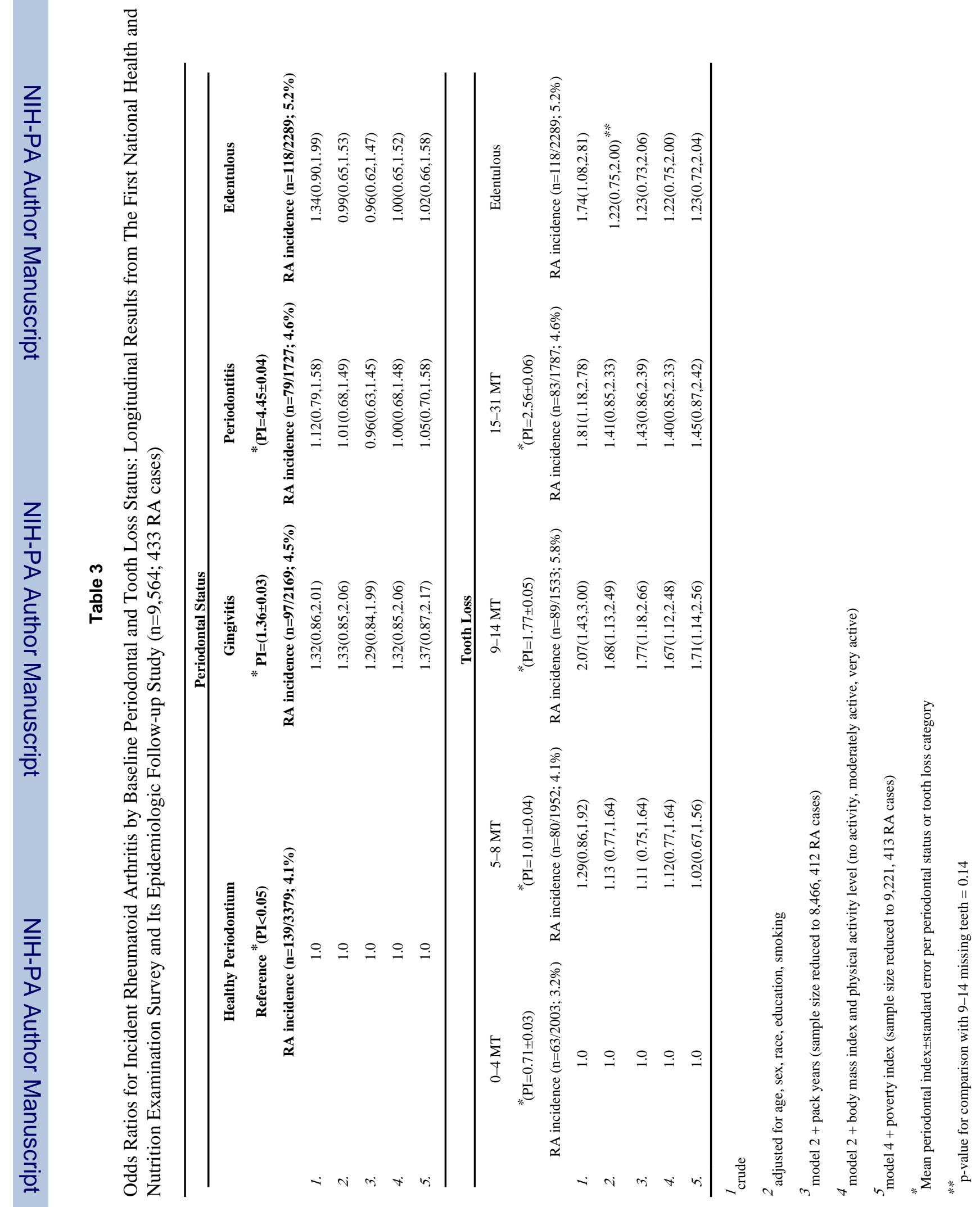




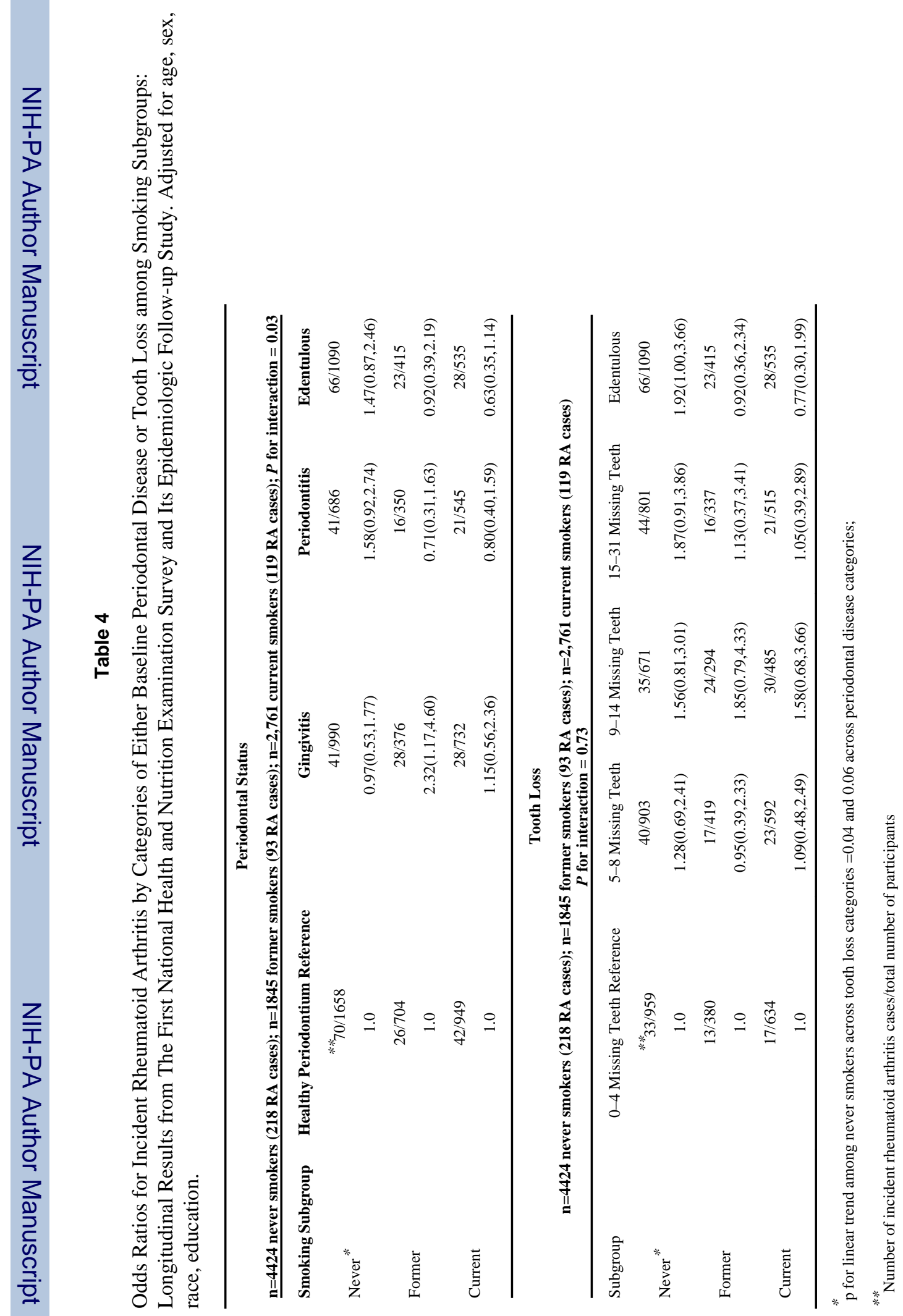

